\title{
Childhood outcomes after prescription of antibiotics to pregnant women with spontaneous preterm labour: 7-year follow-up of the ORACLE II trial
}

\author{
S Kenyon, K Pike, D R Jones, P Brocklehurst, N Marlow, A Salt, D J Taylor
}

\section{Summary}

Background The ORACLE II trial compared the use of erythromycin and/or amoxicillin-clavulanate (co-amoxiclav) with that of placebo for women in spontaneous preterm labour and intact membranes, without overt signs of clinical infection, by use of a factorial randomised design. The aim of the present study-the ORACLE Children Study II-was to determine the long-term effects on children after exposure to antibiotics in this clinical situation.

Methods We assessed children at age 7 years born to the 4221 women who had completed the ORACLE II study and who were eligible for follow-up with a structured parental questionnaire to assess the child's health status. Functional impairment was defined as the presence of any level of functional impairment (severe, moderate, or mild) derived from the mark III Multi-Attribute Health Status classification system. Educational outcomes were assessed with national curriculum test results for children resident in England.

Findings Outcome was determined for 3196 (71\%) eligible children. Overall, a greater proportion of children whose mothers had been prescribed erythromycin, with or without co-amoxiclav, had any functional impairment than did those whose mothers had received no erythromycin (658 [42 . 3\%] of 1554 children vs 574 [38.3\%] of 1498; odds ratio $1 \cdot 18,95 \%$ CI 1.02-1·37). Co-amoxiclav (with or without erythromycin) had no effect on the proportion of children with any functional impairment, compared with receipt of no co-amoxiclav (624 [40.7\%] of 1523 vs 608 [40.0\%] of $1520 ; 1 \cdot 03,0 \cdot 89-1 \cdot 19)$. No effects were seen with either antibiotic on the number of deaths, other medical conditions, behavioural patterns, or educational attainment. However, more children whose mothers had received erythromycin or co-amoxiclav developed cerebral palsy than did those born to mothers who received no erythromycin or no co-amoxiclav, respectively (erythromycin: 53 [3.3\%] of 1611 vs 27 [1.7\%] of 1562, 1.93, 1.21-3.09; co-amoxiclav: 50 [3.2\%] of 1587 vs 30 [1.9\%] of 1586, 1.69, 1.07-2.67). The number needed to harm with erythromycin was 64 (95\% CI 37-209) and with co-amoxiclav 79 (42-591).

Interpretation The prescription of erythromycin for women in spontaneous preterm labour with intact membranes was associated with an increase in functional impairment among their children at 7 years of age. The risk of cerebral palsy was increased by either antibiotic, although the overall risk of this condition was low.

Funding UK Medical Research Council.

\section{Introduction}

Preterm birth is associated with later disabilities among surviving children that pose major challenges for public health and education; these problems increase in frequency as gestational age at birth decreases, ${ }^{1}$ such that around $25 \%$ of babies born before 26 weeks of gestation have serious disability ${ }^{2}$ and many children without serious disability have learning or behavioural difficulties. ${ }^{3,4}$

Observational evidence suggests that perinatal intrauterine infection or inflammation might have a role in the causation of $13-22 \%$ of cases of spontaneous preterm labour (SPL) $)^{5,6}$ and infection or inflammation have been implicated in the genesis of neonatal lung disease $^{7}$ and brain injury. ${ }^{8}$ Despite a number of randomised trials of the use of antibiotics for women with SPL and intact membranes, no clear evidence of benefit has been found and there is some evidence to suggest that such treatment might be associated with increased neonatal mortality. ${ }^{\text {? }}$

ORACLE II ${ }^{10}$ enrolled women who presented with SPL and intact membranes and assessed the use of amoxicillin-clavulanate (co-amoxiclav) $375 \mathrm{mg}$, or erythromycin $250 \mathrm{mg}$, or both, or placebo, four times a day for 10 days or until birth (whichever was soonest), by use of a factorial randomised design. Neither antibiotic was associated with any improvement in neonatal mortality or morbidity. In view of the poor predictive validity of neonatal morbidity after preterm birth for childhood outcome, it is important to determine whether there are long-term sequelae associated with the use, or not, of these antibiotic treatments in women presenting with SPL. We report the results of the ORACLE Children Study II (OCS II), which was designed to assess the long-term outcomes for children born in the UK to women enrolled in the original ORACLE II trial.
Lancet 2008; 372: 1319-27

Published Online September 18,2008 DOI:10.1016/S01406736(08)61203-9

See Comment page 1276 See Articles page 1310 Reproductive Sciences Section, Cancer Studies and Molecular Medicine (S Kenyon MA, K Pike MSc, Prof D J Taylor FRCOG) and Health Sciences Department (Prof D R Jones PhD), University of Leicester, Leicester, UK; National Perinatal Epidemiology Unit, University of Oxford, Oxford, UK (Prof P Brocklehurst FRCOG); Academic Division of Child Health, University of Nottingham, Nottingham, UK (Prof N Marlow FMedSci); Great Ormond Street Hospital for Children and Institute of Child Health, University College London, London, UK (A Salt FRCPCH)

Correspondence to: Sara Kenyon, Reproductive Sciences Section, Cancer Studies and Molecular Medicine University of Leicester, 22-28 Princess Road West, Leicester LE1 6TP, UK oracle@leicester.ac.uk 


\section{Methods} Participants

OCS II began in 2002 and sought follow-up information for children at 7 years of age who were born to the 6241 women who completed the ORACLE II trial..$^{10}$ Tracing and contact of participants in the follow-up study are described in detail in the accompanying paper. ${ }^{11}$

The West Midlands Multi-centre Research and Ethics Committee (MREC) approved the study and the University of Leicester, UK, sponsored the OCS. Oversight was provided by an independent trial steering committee and data monitoring committee, both of which met annually. Those involved in tracing and data entry remained blind to the allocated treatment. All data to assess health and educational outcomes were double entered and subject to validation and logic checks.

\section{Data collection}

Data were collected with a parent-completion postal questionnaire, which consisted of the the Health Utilities Index (HUI), ${ }^{12}$ from which the Multi-Attribute Health Status (MAHS) is derived, the Strengths and Difficulties Questionnaire, ${ }^{13}$ and specific questions on respiratory symptoms,$^{14}$ hospital admissions, convulsions, other specific medical conditions, and demographic data.

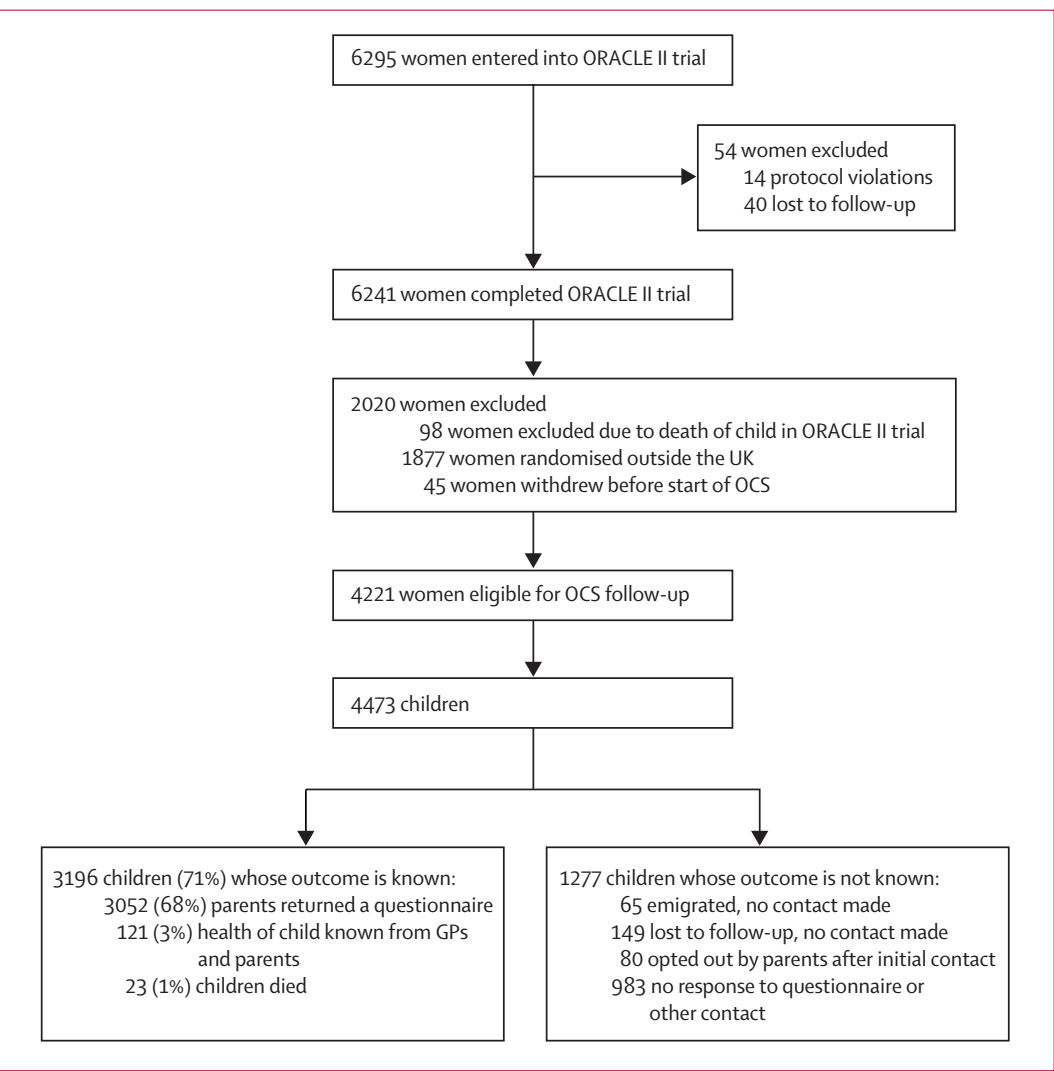

Figure 1: Flowchart for SPL group through ORACLE II and extended follow-up in OCS II

*133 babies died during ORACLE II. However, only 98 women were excluded because a number had a multiple birth. Of the 133 babies, 86 were singletons, 26 multiple births where all babies died (10 sets of twins and two sets of triplets), and 21 were multiple births with live siblings.
The primary outcome was defined as the presence of any level of functional impairment (severe, moderate, or mild) derived from the mark III MAHS classification system ${ }^{12}$ within any of the individual attributes of vision, hearing, speech, ambulation, dexterity, emotion, cognition, or pain. Each attribute has either five or six defined levels of impairment, ranging from normal function to severe dysfunction..$^{15}$ These have been classified further into none, mild, moderate, or severe levels of severity for the individual attributes from the standard algorithms available within the HUI coding/ procedure manual. The overall level of functional impairment was determined by their worst score on any attribute. Sensitivity analyses were also done based on the HUI3 multi-attribute utility scores of overall healthrelated quality of life, ${ }^{16}$ which became available after this study had begun.

Secondary outcomes were the presence of three or more abnormal attributes derived from the MAHS classification system and the degree of functional impairment (severe, moderate, mild, none) within the individual domains; the number of deaths between trial entry and discharge and age 7 years; overall and subscale scores derived from the parent-completed Strengths and Difficulties Questionnaire; the frequency of specific medical conditions including CNS problems (cerebral palsy, fits/seizures, hydrocephalus with a shunt), respiratory problems (wheezing, medication for asthma), hospital admission (both in the last year and for chest problems), diabetes, bowel disorders, and developmental problems (attention deficit hyperactivity disorder derived from the Strengths and Difficulties Questionnaire ${ }^{17}$ or parent report), and other development problems.

We used results from national curriculum tests (key stage one), done at 7 years of age to assess the children's educational attainment for residents in England. ${ }^{18}$ Such tests are not routinely done in other parts of the UK. At key stage one, all children are awarded a level for each of reading, writing, and mathematics. These include levels three and four, which are above average, level two (the average level awarded to $60-70 \%$ of pupils, and which is also subdivided into three sublevels), and below level two, which includes children who attained level one, those who were working towards level one, or who were not entered by the teacher. For all eligible children in England, key stage one level data were provided anonymously by the UK Department for Children, Schools and Families (DCSF), categorised by treatment group.

\section{Statistical analysis}

The size of the study was predefined by the number of women recruited to the ORACLE II trial. The indicative power calculation in the protocol noted that about 4500 children were expected to be eligible for the followup study. About $3.1 \%$ of the children in the any erythromycin group were expected to have three or 


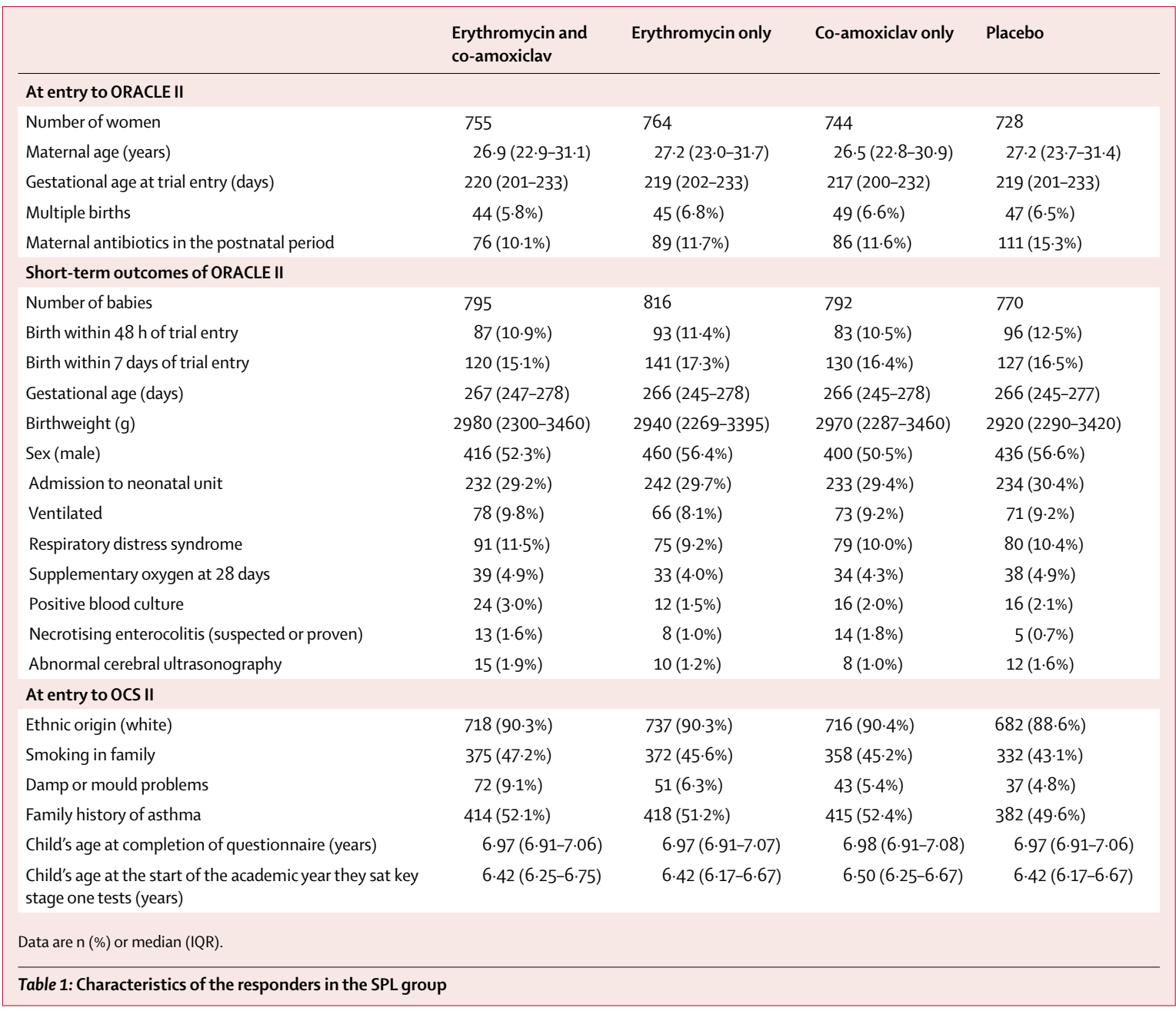

more abnormal attributes using the MAHS scale. ${ }^{12}$ Assuming an $85 \%$ response rate, this gave $80 \%$ power (with two-tailed $\alpha=0.05$ ) to detect a prevalence of three or more abnormal attributes in the no erythromycin group of $5 \%$ (a relative difference between the two groups of $38 \%$ ).

Odds ratios with $95 \% \mathrm{CI}$ are presented for primary and secondary outcomes in the groups receiving co-amoxiclav (any co-amoxiclav: either with or without erythromycin) and erythromycin (any erythromycin: either with or without co-amoxiclav) separately. Odds ratios approximate relative risks when the risk is low. ${ }^{19}$ Logistic models with terms indicating allocation to co-amoxiclav and erythromycin and an interaction term, corresponding to the ORACLE II trial's factorial design, were also fitted. ${ }^{20}$ Since our findings were generally not altered when interaction terms were included, for simplicity they have not been included in models presented in the main tables, but they are available on the internet. Multiple births were treated as being independent in the analyses,

\begin{tabular}{|c|c|c|c|c|c|c|}
\hline & $\begin{array}{l}\text { Any erythromycin } \\
(\mathrm{N}=1554)\end{array}$ & $\begin{array}{l}\text { No erythromycin } \\
(\mathrm{N}=1498)\end{array}$ & OR $(95 \% \mathrm{Cl})$ & $\begin{array}{l}\text { Any co-amoxiclav } \\
(\mathrm{N}=1532)\end{array}$ & $\begin{array}{l}\text { No co-amoxiclav } \\
(\mathrm{N}=1520)\end{array}$ & OR $(95 \% \mathrm{Cl})$ \\
\hline None & $896(57 \cdot 7 \%)$ & $924(61 \cdot 7 \%)$ & Ref & $908(59 \cdot 3 \%)$ & $912(60.0 \%)$ & Ref \\
\hline Any functional impairment & $658(42 \cdot 3 \%)$ & $574(38 \cdot 3 \%)$ & $1.18(1.02-1 \cdot 37)$ & $624(40 \cdot 7 \%)$ & $608(40 \cdot 0 \%)$ & $1.03(0.89-1.19)$ \\
\hline Mild & $372(23 \cdot 9 \%)$ & $319(21 \cdot 3 \%)$ & $1.20(1.01-1.43)$ & $349(22 \cdot 8 \%)$ & $342(22 \cdot 5 \%)$ & $1.02(0.86-1.22)$ \\
\hline Moderate & $185(11 \cdot 9 \%)$ & $162(10 \cdot 8 \%)$ & $1.18(0.94-1.48)$ & $176(11 \cdot 5 \%)$ & $171(11 \cdot 3 \%)$ & $1.03(0.82-1.30)$ \\
\hline Severe & $101(6 \cdot 5 \%)$ & $93(6 \cdot 2 \%)$ & $1.12(0.83-1.51)$ & $99(6 \cdot 5 \%)$ & $95(6 \cdot 3 \%)$ & $1.05(0.78-1.41)$ \\
\hline $\begin{array}{l}\text { Three or more abnormal } \\
\text { attributes }\end{array}$ & $131(8 \cdot 4 \%)$ & $149(9 \cdot 9 \%)$ & $0.83(0.65-1.07)$ & $147(9 \cdot 6 \%)$ & $133(8 \cdot 8 \%)$ & $1.11(0.87-1.42)$ \\
\hline
\end{tabular}




\begin{tabular}{|c|c|c|c|c|c|c|}
\hline & Any erythromycin & No erythromycin & OR $(95 \% \mathrm{Cl})$ & Any co-amoxiclav & No co-amoxiclav & OR $(95 \% \mathrm{Cl})$ \\
\hline Number of women & 2219 & 2145 & & 2158 & 2206 & \\
\hline Number of children & 2375 & 2279 & & 2304 & 2350 & \\
\hline Stillbirths & $20(0.8 \%)$ & $24(1 \cdot 1 \%)$ & $0.80(0.44-1.45)$ & $20(0.9 \%)$ & $24(1.0 \%)$ & $0.85(0.47-1.54)$ \\
\hline Deaths in first year & $61(2 \cdot 6 \%)$ & $41(1 \cdot 8 \%)$ & $1.44(0.96-2 \cdot 14)$ & $49(2 \cdot 1 \%)$ & $53(2 \cdot 3 \%)$ & $0.94(0.63-1.39)$ \\
\hline Deaths after first year & $5(0 \cdot 2 \%)$ & $5(0 \cdot 2 \%)$ & $0.97(0.28-3.34)$ & $6(0 \cdot 3 \%)$ & $4(0 \cdot 2 \%)$ & $1.53(0.43-5.42)$ \\
\hline Total deaths & $86(3.6 \%)$ & $70(3 \cdot 1 \%)$ & $1.19(0.86-1.63)$ & $75(3 \cdot 3 \%)$ & $81(3 \cdot 4 \%)$ & $0.94(0.68-1.30)$ \\
\hline Total death or any functional impairment & $744(31 \cdot 3 \%)$ & $644(28 \cdot 3 \%)$ & $1 \cdot 16(1 \cdot 02-1 \cdot 31)$ & $699(30 \cdot 3 \%)$ & $689(29 \cdot 3 \%)$ & $1.05(0.93-1.19)$ \\
\hline Total death or three or more abnormal attributes & $217(9 \cdot 1 \%)$ & $219(9 \cdot 6 \%)$ & $0.95(0.78-1.15)$ & $222(9 \cdot 6 \%)$ & $214(9 \cdot 1 \%)$ & $1.06(0.87-1 \cdot 30)$ \\
\hline Total death or cerebral palsy & $139(5 \cdot 9 \%)$ & $97(4 \cdot 3 \%)$ & $1.40(1.07-1.82)$ & $125(5 \cdot 4 \%)$ & $111(4 \cdot 7 \%)$ & $1.16(0.89-1 \cdot 50)$ \\
\hline
\end{tabular}

\begin{tabular}{|c|c|c|c|c|c|c|c|c|}
\hline & $\begin{array}{l}\text { Erythromycin and } \\
\text { co-amoxiclav }(\mathrm{N}=769)\end{array}$ & OR $(95 \% \mathrm{Cl})^{*}$ & $\begin{array}{l}\text { Erythromycin } \\
\text { only }(\mathrm{N}=785)\end{array}$ & OR $(95 \% \mathrm{Cl})^{*}$ & $\begin{array}{l}\text { Co-amoxiclav } \\
\text { only }(\mathrm{N}=763)\end{array}$ & OR $(95 \% \mathrm{Cl})^{*}$ & $\begin{array}{l}\text { Double placebo } \\
(\mathrm{N}=735)\end{array}$ & $\begin{array}{l}\text { OR } \\
(95 \% \mathrm{Cl})^{*}\end{array}$ \\
\hline None & $444(57 \cdot 7 \%)$ & $0.82(0.66-1.00)$ & $452(57 \cdot 6 \%)$ & $0.81(0.66-1.00)$ & $464(60 \cdot 8 \%)$ & $0.93(0.75-1.14)$ & $460(62 \cdot 6 \%)$ & Ref \\
\hline Any functional impairment & $325(42 \cdot 3 \%)$ & $1.22(1.00-1 \cdot 51)$ & $333(42 \cdot 4 \%)$ & $1.23(1 \cdot 00-1 \cdot 51)$ & $299(39 \cdot 2 \%)$ & $1.08(0.88-1.33)$ & $275(37 \cdot 4 \%)$ & Ref \\
\hline Mild & $181(23 \cdot 5 \%)$ & $1.24(0.96-1.60)$ & $191(24 \cdot 3 \%)$ & $1.29(1.00-1 \cdot 65)$ & $168(22 \cdot 0 \%)$ & $1.10(0.85-1.42)$ & $151(20 \cdot 5 \%)$ & Ref \\
\hline Moderate & $91(11 \cdot 8 \%)$ & $1.22(0.88-1 \cdot 70)$ & $94(12 \cdot 0 \%)$ & $1.24(0.89-1.72)$ & $85(11 \cdot 1 \%)$ & $1.09(0.78-1.53)$ & $77(10 \cdot 5 \%)$ & Ref \\
\hline Severe & $53(6 \cdot 9 \%)$ & $1.17(0 \cdot 77-1 \cdot 77)$ & $48(6 \cdot 1 \%)$ & $1.04(0.68-1.59)$ & $46(6 \cdot 0 \%)$ & $0.97(0.63-1.49)$ & $47(6 \cdot 4 \%)$ & Ref \\
\hline Three or more abnormal attributes & $72(9 \cdot 4 \%)$ & $0.92(0.66-1.30)$ & $59(7 \cdot 5 \%)$ & $0.73(0.51-1.04)$ & $75(9 \cdot 8 \%)$ & $0.97(0.69-1.37)$ & $74(10 \cdot 1 \%)$ & Ref \\
\hline
\end{tabular}

For more on indices of deprivation see http://www. neighbourhood.statistics.gov.uk but sensitivity analyses based on randomly selecting one child were also done. ${ }^{21}$

Data from the Strengths and Difficulties Questionnaire were classified as normal, borderline, or abnormal. Odds ratios and $\mathrm{CI}$ for proportions with borderline or abnormal scores are presented. Models with interaction terms are also fitted as above.

Subgroup analyses were done as specified in the protocol, relating to multiple and singleton pregnancies, and gestational age subgroups used at the time of randomisation ( $<32$ weeks' gestation and $<28$ weeks' gestation).

Relative risks and 95\% CI for key stage one educational data were obtained from Poisson regression models, adjusting for test year. Because of restricted information available from the anonymous summary of these data supplied by the DCSF, sensitivity and subgroup analyses were not possible for these data.

Most of the outcomes presented, including the primary outcome of the follow-up study, can only be assessed in surviving children. Thus the analyses presented are not based on the intention-to-treat principle (ie, by analysis of outcomes in all those entered into the trial). However, the absolute risk of death was low, limiting any potential bias that might be introduced by undertaking the analyses of surviving children only, as pre-specified in the study protocol. There were no clear differences in the numbers of deaths in each of the study groups at the end of the ORACLE II trial, but we present sensitivity analyses using a composite death or any functional impairment outcome to confirm the limited effect of including deaths in the analyses.

Informal allowance for the large number of comparisons undertaken is made in interpreting the results throughout. ${ }^{22}$

Outcomes for children not assessed may differ from outcomes for those who were assessed..$^{23}$ To explore this, we investigated differences between responders and nonresponders for a variety of factors: treatment group, short-term maternal and neonatal outcomes, ethnicity, indices of deprivation from ONS derived from post code, and for those children in England, educational attainment.

\section{Role of the funding source}

The study sponsors had no involvement in the study design; collection, analysis, and interpretation of the data; in the writing of the report; and in the decision to submit the paper for publication. DJ and KP had full access to all the data. SK had final responsibility for the decision to submit for publication.

\section{Results}

Of the 4473 UK children eligible for follow-up, outcome was known for 3196 (71\%): 3052 (68\%) parents returned a questionnaire, data were collected from telephone interview or the family doctor for 121 (3\%) children (included in the analysis of specific medical conditions), and $23(1 \%)$ died (figure 1). Women were unaware of their treatment allocation, with the exception of three people 
who requested this information before returning data for this study. Only $0.6 \%$ of data within returned questionnaires were missing. Full key stage one level data were available for 3239 (95\%) of the 3394 children in England who had been entered for the tests by 2007. The characteristics of the responders to the questionnaires were broadly similar to the total population enrolled in the ORACLE II trial (table 1), but mothers in the double placebo group were less likely to be white, and received more postnatal antibiotics than those in the other groups (table 1).

Children whose outcome was unknown had younger mothers and had less neonatal morbidity (webtable 1), and at least for those in England, were from more deprived areas than those whose outcome was known (webtable 2). More English children whose outcome was unknown scored below level two in key stage one tests and were less likely to be white than were those whose outcome was known (webtable 2).

More children whose mothers had received any erythromycin had any functional impairment than did those whose mothers received no erythromycin (table 2). The proportion of children categorised as having moderate or severe functional impairment, or with three or more abnormal attributes, did not vary markedly between treatment groups, but the proportion of children with mild functional impairment was higher in the any erythromycin group than in the no erythromycin group (table 2). Findings were similar for the composite outcome of death or any functional impairment (table 3). Sensitivity analyses based on the HUI3 multi-attribute utility function ${ }^{16}$ lead to broadly similar results (webtable 3 ).
By contrast, there was no difference between children whose mothers had received any co-amoxiclav and those whose mothers had received no co-amoxiclav in terms of the proportion of children with any functional impairment; in the categories of mild, moderate, severe, or three or more abnormal attributes; or when functional impairment was combined with death (table 2 and table 3).

These findings were supported when fitting a logistic model with terms for erythromycin, co-amoxiclav, and an interaction between the two drugs (webtable 4); there was no evidence of an interaction in effects between the drugs (webtable 4). Results were consistent when missing data were assumed to correspond to a functional impairment (data not shown). Table 4 presents the results of the four treatment groups "inside the table" of the factorial trial; ${ }^{24}$ again, increases in functional impairment were seen with the prescription of erythromycin.

The number of deaths (table 3; webtable 5), behaviour (table 5; webtable 6), educational attainment (table 6), and non-neurological conditions (table 7; webtable 7) did not differ between children whose mothers had received any erythromycin, compared with those whose mothers had received no erythromycin, except for more children presenting with bowel disorders if their mother had received any erythromycin. Receipt of co-amoxiclav seemed to have no effect on any of these outcomes, compared with receipt of no co-amoxiclav (tables 3, 5-7).

However, more children whose mothers had received any erythromycin or whose mothers had received any co-amoxiclav had cerebral palsy than did those whose mothers had received no erythromycin or no

\begin{tabular}{|c|c|c|c|c|c|c|}
\hline & $\begin{array}{l}\text { Any erythromycin } \\
(\mathrm{N}=1554)\end{array}$ & $\begin{array}{l}\text { No erythromycin } \\
(\mathrm{N}=1498)\end{array}$ & OR $(95 \% \mathrm{Cl})$ & $\begin{array}{l}\text { Any co-amoxiclav } \\
(\mathrm{N}=1532)\end{array}$ & $\begin{array}{l}\text { No co-amoxiclav } \\
(\mathrm{N}=1520)\end{array}$ & OR $(95 \% \mathrm{Cl})$ \\
\hline Emotional symptoms & $327(21.0 \%)$ & $330(22 \cdot 0 \%)$ & $0.94(0.79-1.12)$ & $341(22 \cdot 3 \%)$ & $316(20 \cdot 8 \%)$ & $1.09(0.92-1 \cdot 30)$ \\
\hline Conduct problems & $480(30 \cdot 9 \%)$ & $420(28.0 \%)$ & $1.15(0.98-1 \cdot 34)$ & $454(29 \cdot 6 \%)$ & $446(29 \cdot 3 \%)$ & $1.01(0.87-1.18)$ \\
\hline Hyperactivity & $424(27 \cdot 3 \%)$ & $415(27 \cdot 7 \%)$ & $0.98(0.84-1.15)$ & $418(27 \cdot 3 \%)$ & $421(27 \cdot 7 \%)$ & $0.98(0.84-1.15)$ \\
\hline Peer problems & $405(26 \cdot 1 \%)$ & $391(26 \cdot 1 \%)$ & $1.00(0.85-1.17)$ & $396(25 \cdot 8 \%)$ & $400(26 \cdot 3 \%)$ & $0.98(0.83-1.15)$ \\
\hline Prosocial behaviour & $122(7 \cdot 9 \%)$ & $99(6 \cdot 6 \%)$ & $1.20(0.91-1.59)$ & $112(7 \cdot 3 \%)$ & $109(7 \cdot 2 \%)$ & $1.02(0.78-1.34)$ \\
\hline Overall (total difficulties) & $384(24 \cdot 7 \%)$ & $363(24 \cdot 2 \%)$ & $1.03(0.87-1.21)$ & $385(25 \cdot 1 \%)$ & $362(23 \cdot 8 \%)$ & $1.07(0.91-1.27)$ \\
\hline Impact on families & $334(21 \cdot 5 \%)$ & $292(19 \cdot 5 \%)$ & $1.13(0.95-1.35)$ & $312(20 \cdot 4 \%)$ & $314(20 \cdot 7 \%)$ & $0.98(0.82-1.17)$ \\
\hline
\end{tabular}

\begin{tabular}{|c|c|c|c|c|c|c|}
\hline & $\begin{array}{l}\text { Any erythromycin } \\
(\mathrm{N}=1641)\end{array}$ & $\begin{array}{l}\text { No erythromycin } \\
(\mathrm{N}=1598)\end{array}$ & $\mathrm{RR}(95 \% \mathrm{Cl})$ * & $\begin{array}{l}\text { Any co-amoxiclav } \\
(\mathrm{N}=1608)\end{array}$ & $\begin{array}{l}\text { No co-amoxiclav } \\
(\mathrm{N}=1631)\end{array}$ & $\operatorname{RR}(95 \% \mathrm{Cl})^{*}$ \\
\hline Reading & $377(23.0 \%)$ & $367(23.0 \%)$ & $1.00(0.96-1.04)$ & $366(22 \cdot 8 \%)$ & $378(23 \cdot 2 \%)$ & $0.99(0.95-1.03)$ \\
\hline Writing & $413(25 \cdot 2 \%)$ & $413(25 \cdot 8 \%)$ & $1.00(0.97-1.04)$ & $395(24 \cdot 6 \%)$ & $431(26 \cdot 4 \%)$ & $0.99(0.95-1.02)$ \\
\hline Maths & $239(14 \cdot 6 \%)$ & $225(14 \cdot 1 \%)$ & $0.99(0.96-1.03)$ & $230(14 \cdot 3 \%)$ & $234(14 \cdot 3 \%)$ & $0.99(0.95-1.03)$ \\
\hline
\end{tabular}




\begin{tabular}{|c|c|c|c|c|c|c|}
\hline & $\begin{array}{l}\text { Any erythromycin } \\
(\mathrm{N}=1611)\end{array}$ & $\begin{array}{l}\text { No erythromycin } \\
(\mathrm{N}=1562)\end{array}$ & OR $(95 \% \mathrm{Cl})$ & $\begin{array}{l}\text { Any co-amoxiclav } \\
(\mathrm{N}=1587)\end{array}$ & $\begin{array}{l}\text { No co-amoxiclav } \\
(\mathrm{N}=1586)\end{array}$ & $\mathrm{OR}(95 \% \mathrm{Cl})$ \\
\hline \multicolumn{7}{|l|}{ CNS problems } \\
\hline Cerebral palsy & $53(3 \cdot 3 \%)$ & $27(1 \cdot 7 \%)$ & $1.93(1.21-3.09)$ & $50(3 \cdot 2 \%)$ & $30(1.9 \%)$ & $1.69(1.07-2.67)$ \\
\hline Seizures & $149(9 \cdot 2 \%)$ & $116(7 \cdot 4 \%)$ & $1.27(0.99-1.64)$ & $144(9 \cdot 1 \%)$ & $121(7 \cdot 6 \%)$ & $1.21(0.94-1.56)$ \\
\hline On prescribed medication & $27(1.7 \%)$ & $17(1 \cdot 1 \%)$ & $1.55(0.84-2 \cdot 85)$ & $22(1 \cdot 4 \%)$ & $22(1.4 \%)$ & $1.00(0.55-1.81)$ \\
\hline Hydrocephalus with shunt & $2(0 \cdot 1 \%)$ & $3(0 \cdot 2 \%)$ & $0.65(0.11-3 \cdot 87)$ & $4(0 \cdot 3 \%)$ & $1(0 \cdot 1 \%)$ & $4.01(0.45-35.87)$ \\
\hline \multicolumn{7}{|l|}{ Developmental problems } \\
\hline ADHD from SDQ or parental report & $120(7 \cdot 4 \%)$ & $116(7 \cdot 4 \%)$ & $1.00(0.77-1 \cdot 31)$ & $128(8 \cdot 1 \%)$ & $108(6 \cdot 8 \%)$ & $1.20(0.92-1.57)$ \\
\hline Other developmental problems & $10(0 \cdot 6 \%)$ & $15(1.0 \%)$ & $0.64(0.29-1.44)$ & $8(0.5 \%)$ & $17(1 \cdot 1 \%)$ & $0.47(0.20-1.09)$ \\
\hline \multicolumn{7}{|l|}{ Respiratory problems } \\
\hline Wheezing in last year & $295(18 \cdot 3 \%)$ & $295(18.9 \%)$ & $0.96(0.81-1.15)$ & $291(18 \cdot 3 \%)$ & $299(18.9 \%)$ & $0.97(0.81-1.16)$ \\
\hline $\begin{array}{l}\text { Medication for chest problems in } \\
\text { last year }\end{array}$ & $262(16 \cdot 3 \%)$ & $280(17.9 \%)$ & $0.89(0.74-1.07)$ & $257(16 \cdot 2 \%)$ & $285(18.0 \%)$ & $0.88(0.73-1.06)$ \\
\hline Prednisolone & $29(1.8 \%)$ & $33(2 \cdot 1 \%)$ & $0.85(0.51,1.41)$ & $28(1.8 \%)$ & $34(2 \cdot 1 \%)$ & $0.82(0.49,1.36)$ \\
\hline Oxygen & $22(1.4 \%)$ & $22(1.4 \%)$ & $0.97(0.53-1.76)$ & $17(1 \cdot 1 \%)$ & $28(1.8 \%)$ & $0.60(0.33-1.11)$ \\
\hline Relievers & $235(14 \cdot 6 \%)$ & $259(16 \cdot 6 \%)$ & $0.86(0.71-1.04)$ & $244(15 \cdot 4 \%)$ & $250(15 \cdot 8 \%)$ & $0.97(0.80-1.18)$ \\
\hline Preventers & $182(11 \cdot 3 \%)$ & $199(12 \cdot 7 \%)$ & $0.87(0.70-1.08)$ & $186(11 \cdot 7 \%)$ & $195(12 \cdot 3 \%)$ & $0.95(0.76-1.17)$ \\
\hline \multicolumn{7}{|l|}{ Hospital admission } \\
\hline Admission to hospital in last year & $243(15 \cdot 1 \%)$ & $202(12 \cdot 9 \%)$ & $1.20(0.98-1.46)$ & $220(13 \cdot 9 \%)$ & $225(14 \cdot 2 \%)$ & $0.97(0.80-1.19)$ \\
\hline Admission for chest problems & $32(2.0 \%)$ & $38(2 \cdot 4 \%)$ & $0.81(0.51-1.31)$ & $33(2 \cdot 1 \%)$ & $37(2 \cdot 3 \%)$ & $0.89(0.55-1.43)$ \\
\hline \multicolumn{7}{|l|}{ Diabetes } \\
\hline Diabetes & $0(0.0 \%)$ & $2(0 \cdot 1 \%)$ & .. & $2(0 \cdot 1 \%)$ & $0(0.0 \%)$ & .. \\
\hline \multicolumn{7}{|l|}{ Bowel disorders } \\
\hline All bowel problems & $64(4 \cdot 0 \%)$ & $38(2 \cdot 4 \%)$ & $1 \cdot 66(1 \cdot 10-2 \cdot 49)$ & $54(3 \cdot 4 \%)$ & $48(3.0 \%)$ & $1.13(0.76-1.68)$ \\
\hline Bowel stoma & $24(1.5 \%)$ & $13(0 \cdot 8 \%)$ & $1.80(0.91-3 \cdot 55)$ & $21(1 \cdot 3 \%)$ & $16(1 \cdot 0 \%)$ & $1 \cdot 32(0.68-2.53)$ \\
\hline Other bowel problems & $40(2.5 \%)$ & $25(1.6 \%)$ & $1.57(0.95-2.59)$ & $33(2 \cdot 1 \%)$ & $32(2.0 \%)$ & $1.03(0.63-1.69)$ \\
\hline
\end{tabular}

co-amoxiclav, respectively (table 7). A logistic model with erythromycin, co-amoxiclav, and treatment interaction terms suggested that there was no evidence of an interaction between the two antibiotics (webtable 7). However, the study is underpowered to test the interaction term and thus further examination of results "inside the table" was done. ${ }^{24}$ These analyses suggest

\begin{tabular}{|c|c|c|c|c|}
\hline & $\begin{array}{l}\text { Erythromycin and } \\
\text { co-amoxiclav }(\mathrm{N}=35)\end{array}$ & $\begin{array}{l}\text { Erythromycin } \\
\text { only }(\mathrm{N}=18)\end{array}$ & $\begin{array}{l}\text { Co-amoxiclav } \\
\text { only }(\mathrm{N}=15)\end{array}$ & $\begin{array}{l}\text { Double placebo } \\
(\mathrm{N}=12)\end{array}$ \\
\hline None & $1(2 \cdot 9 \%)$ & $1(5 \cdot 6 \%)$ & $1(6 \cdot 7 \%)$ & $0(0 \cdot 0 \%)$ \\
\hline Any functional impairment & $33(94 \cdot 3 \%)$ & $16(88.9 \%)$ & $12(80 \cdot 0 \%)$ & $12(100 \cdot 0 \%)$ \\
\hline Mild & $4(11 \cdot 4 \%)$ & $2(11 \cdot 1 \%)$ & $0(0 \cdot 0 \%)$ & $1(8 \cdot 3 \%)$ \\
\hline Moderate & $10(28 \cdot 6 \%)$ & $3(16 \cdot 7 \%)$ & $1(6 \cdot 7 \%)$ & $3(25 \cdot 0 \%)$ \\
\hline Severe & $19(54 \cdot 3 \%)$ & $11(61 \cdot 1 \%)$ & $11(73 \cdot 3 \%)$ & $8(66 \cdot 7 \%)$ \\
\hline \multicolumn{5}{|c|}{ Children scoring severe functional impairment do so in the following domains } \\
\hline Ambulation & $18(51 \cdot 4 \%)$ & $9(50 \cdot 0 \%)$ & $7(46 \cdot 7 \%)$ & $5(41 \cdot 7 \%)$ \\
\hline Dexterity & $6(17 \cdot 1 \%)$ & $6(33 \cdot 3 \%)$ & $8(53 \cdot 3 \%)$ & $3(25 \cdot 0 \%)$ \\
\hline Cognition & $5(14 \cdot 3 \%)$ & $0(0.0 \%)$ & $4(26 \cdot 7 \%)$ & $4(33 \cdot 3 \%)$ \\
\hline Pain & $5(14 \cdot 3 \%)$ & $3(16 \cdot 7 \%)$ & $3(20.0 \%)$ & $4(33 \cdot 3 \%)$ \\
\hline
\end{tabular}

Functional impairment outcomes are not available for four children for whom a questionnaire was not returned (one in both antibiotics group, one in erythromycin only group, and two in the co-amoxiclav only group).

Table 8: Functional impairment outcomes of the children with cerebral palsy whose mothers had SPL that more children who developed cerebral palsy had been born to mothers who had received both antibiotics ( 35 children) than to mothers who received erythromycin only (18 children), co-amoxiclav only (15 children), or double placebo (12 children). Although there is evidence of an excess risk in the both antibiotics group compared with double placebo (OR 2.91, 1.50-5.65), there is insufficient power to exclude an excess risk in those exposed to either drug alone (erythromycin alone: OR 1.42 , $95 \%$ CI $0.68-2.98$; co-amoxiclav alone: 1.22 , $0 \cdot 57-2 \cdot 62$ )

In this study the number needed to harm in the any erythromycin group was 64 (95\% CI 37-209) and in the any co-amoxiclav group was 79 (42-591). In view of the unexpected excess of cerebral palsy associated with antibiotic prescription, further exploratory analyses of the characteristics of the children with cerebral palsy, and of risk factors for this condition, were done. The excess of cases of cerebral palsy was not offset by a lower number of deaths in the any erythromycin group: death and cerebral palsy were both increased in the any erythromycin group (table 3 ). There is no evidence that the children reported with cerebral palsy in the combined antibiotic group were more severely affected than were those in the other treatment groups (table 8). Analysis of 


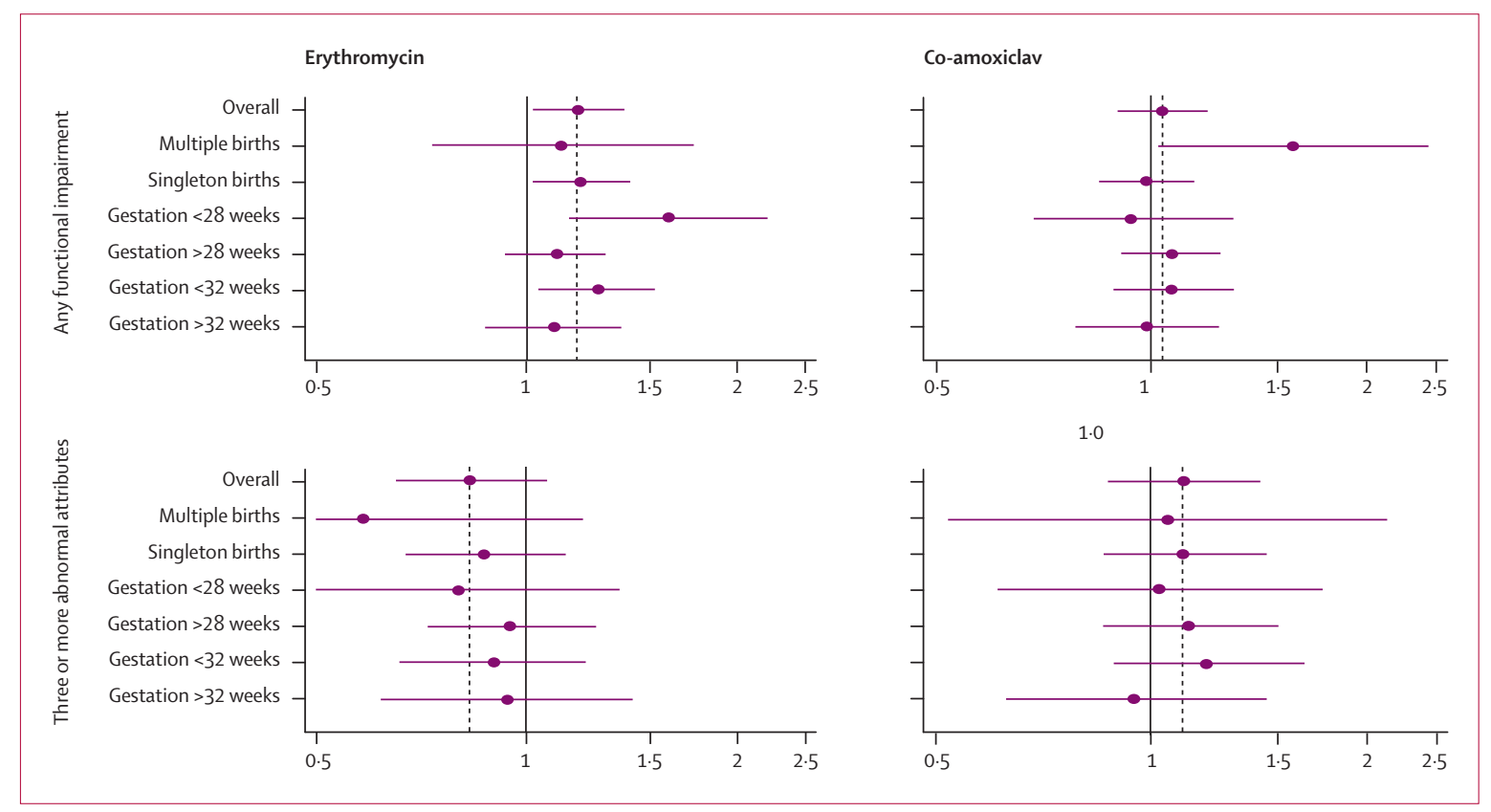

Figure 2: Subgroup analyses for overall functional impairment in children whose mothers had SPL

individual HUI attributes did not show any treatment effects; the attributes for which children with cerebral palsy were most commonly categorised as having severe functional impairment were ambulation, dexterity, cognition, and pain (table 8).

Children with cerebral palsy were more likely to be have been born to women recruited at earlier gestations, and to be born sooner after the enrolment of the mother than were children without cerebral palsy (webtable 8). Maternal antibiotic prescription for postnatal infection was more likely for children with cerebral palsy than for those without; the duration of time from trial entry to birth was more likely to be less than 1 day or between 1 and 10 days for children with cerebral palsy than for those without (webtable 8). Babies with cerebral palsy were more likely to be male and to be admitted to a neonatal intensive care unit than were those without, and, as anticipated, were at increased risk of associated neonatal morbidity (webtable 8).

By contrast with the cerebral palsy group as a whole, more detailed "inside the table" comparisons show more children with cerebral palsy whose mothers had received both antibiotics were entered into the trial between 28 and 32 weeks of gestation than were those whose mothers received one or other of the antibiotics, or who had received placebo (webtable 8 ). Further examination of this group ( 24 children) showed an excess in the both antibiotic group of those that had cervical dilation 0 to $1 \mathrm{~cm}$ at recruitment, who received the randomised treatment for 10 days, and who were born after 32 weeks (webtable 9).

Subgroup analyses for multiple versus singleton births and for gestation above and below 28 and 32 weeks at randomisation were pre-planned (figure 2). The increased risk of functional impairment observed after receipt of any erythromycin is most clearly apparent in singleton births and those children who were born at low gestational age, with sampling variation being larger in the small multiple birth and other gestational age subgroups. Adjustment for maternal baseline, social class, and other factors did not substantially alter the treatment effects noted (data not shown). For further analyses, see http:// www2.le.ac.uk/Members/drj/supplementary-materialsfor-papers.

\section{Discussion}

In this long-term follow-up of children whose mothers took part in the ORACLE II trial of antibiotics for preterm labour in the presence of intact membranes, we found an unexpected increase in the number of children with any functional impairment who were exposed to erythromycin. Furthermore, we found an increased prevalence of cerebral palsy (as reported by parents) associated with treatment with either antibiotic; there is some evidence to suggest that there is an additive effect in the children of mothers who received both antibiotics. Although formal evidence of an interaction between the two antibiotics is lacking, and the power of the study to detect such interactions is low, the excess of children with cerebral palsy born to mothers who received both antibiotics is clear enough to suggest that this should not be dismissed as a chance result of multiple testing. While a Bonferroni correction ${ }^{24}$ (based on a family size of ten main comparisons per treatment, as in table 7) might suggest that chance cannot be ruled out as an explanation, there are a number of features that suggest it would be
See Online for webtable 8 
unwise to dismiss the excess of cerebral palsy as a chance finding. These include a potential dose-response relationship (if the subgroup receiving both antibiotics is regarded as having received a higher dose of antibiotic), biological plausibility, and possibly specificity to cerebral palsy. There is also evidence to suggest that the treatment effect seen here is not simply a result of a spuriously low rate of cerebral palsy in the placebo group-stratified data from a register of children with cerebral palsy in four counties in the UK suggest that 7.5 cases would have been expected, compared with the 12 cases observed. ${ }^{25}$ These results provide strong evidence for the importance of childhood follow-up of perinatal and neonatal trials and interventions.

We chose to obtain proxy information about the children from parents because the size of the study population made individualised assessment both impractical and prohibitively expensive. Where possible we used well validated and standardised instruments, ${ }^{12,13}$ but use of a questionnaire could mean it was not possible to detect more subtle differences between treatment groups, nor has it been possible to confirm the findings. In spite of not having face-to-face contact, we achieved an acceptable follow-up rate of $71 \%$ by maintaining regular contact with the women originally entered into the trial. Although we attempted to minimise non-response, disadvantaged groups are over-represented in the nonresponders. There is evidence to suggest that outcomes for children assessed with difficulty might differ from those assessed with ease. ${ }^{23}$ However, there was no evidence of differential response bias and most women remained unaware of their treatment allocation. Despite the response rate being lower than that assumed in the initial power calculation, the increased prevalence of functional impairment resulted in power being increased overall.

The results of this study must be viewed within the clinical context of this group of women. First, the accurate diagnosis of SPL was and remains imperfect, as many women who present with painful preterm uterine contractions do not give birth preterm. This was the case in this study, where almost $64 \%$ of women who were entered into the ORACLE II trial gave birth after 37 weeks of gestation. Second, the proportion of women who had subclinical intrauterine infection at the time of randomisation is not known; however, it will probably have been low $\left(13-22 \% \%^{5,6}\right)$.

Why receipt of antibiotics increased the risk of functional impairment and cerebral palsy in a population at low risk of intrauterine infection is unclear. We suggest a number of pathways, although others will no doubt emerge. Length of exposure to antibiotics for this group of women was fairly long, with 15-20\% giving birth within 7 days. $^{10}$ An episode of preterm labour which settles could genuinely reflect an infective episode, where maternal defences-facilitated by antibiotics - overcome the insult, thus prolonging pregnancy, but not necessarily resolving the associated intrauterine and fetal inflammation. A continuing inflammatory environment could have led to fetal brain injury and thereby cerebral palsy. Alternatively, cerebral palsy could have resulted from a direct effect of the antibiotics themselves; erythromycin, for example, has significant effects on the cardiovascular system-eg, arrythmias-which could have led to cerebral ischaemic events and thereby cerebral palsy. ${ }^{26}$ It is also possible that the episode of SPL was not associated with infection, but rather with other pathologies within the so-called preterm parturition syndrome, ${ }^{6}$ which might have been exacerbated by the antibiotics by as yet undetermined mechanisms.

The results of this study add weight to the argument that we should be vigilant about interfering with systems we poorly understand in the absence of benefit. For example, there is little known about the effect of antibiotics on early patterns of microbial colonisation of newborn children, which might have important, longlasting consequences for early human development. ${ }^{27}$ Whatever the causal pathway, the findings in our study, together with concerns about the potential increase in neonatal mortality, ${ }^{9}$ support the opinion that antibiotics are not advisable in SPL without clinical signs of infection. Indeed, in the UK, women are not routinely prescribed antibiotics if they have intact membranes, although there are no national guidelines; likewise, in the USA, antibiotics are not recommended in preterm labour. ${ }^{28}$ Nonetheless, it is critical that women with evidence of clinical infection are treated with antibiotics, since clinical chorioamnionitis remains an important cause of maternal, fetal, and neonatal death. The results of this study should not lead to fewer women with overt signs of maternal or fetal infection receiving treatment.

Contributors

All authors contributed to the study design, developed the protocol, and contributed to drafting the paper. SK led the study and together with DJT and $\mathrm{PB}$ contributed knowledge of maternity practice. KP and DRJ provided statistical knowledge; NM and AS contributed knowledge on childhood outcomes.

\section{OCS II Study Team}

OCS Office: Ann Blackburn, Kate Taylor, and the office staff. Department of Health Sciences, University of Leicester: Mary Dixon Woods, Carolyn Tarrant, Clare Jackson, Janet Willars.

Trial steering committee: Richard Lilford, Richard Cooke, Gill Gyte, Chris Whetton, Philippa Russell, Julie Cahill.

Data monitoring committee: Diana Elbourne, Helena McNally, Martin Whittle.

\section{Conflict of interest statement}

We declare that we have no conflict of interest.

\section{Acknowledgments}

This study was funded by the UK Medical Research Council and sponsored by University Hospitals of Leicester and approved by their research and development directorate. We thank all the women and children who took part in the study and the obstetricians and midwives who recruited them to the original ORACLE trials. We thank the Office of National Statistics, the NHS National Strategic Tracing Service, and the Data Services Group within the Department of Children, Schools and Families. We also thank the key stage one group (Maggie McLean, John Crookes, Peter Tymms, and Tony Cline) for helpful comments on educational aspects. We thank Steve Gould, Barbara Farrell, 
Phil Edwards, and Martin Rosser for advice on questionnaire design. We convened a group of experts from within the field to help us understand and interpret these finding before publication. This group consisted of Martin Whittle, Alison Bedford Russell, Phil Bennett, Kate Costeloe, Francis Cowan, Olaf Dammann, Diana Elbourne, Catherine Elliott, Mike Millar, Jane Norman, Micheal O'Shea, Max Parmar, Roberto Romero, and Dieter Wolke.

\section{References}

1 Salt AT, Redshaw M. Neurodevelopment follow-up after preterm birth: follow up after two years. Early Hum Dev 2006; 82: 185-97.

2 Marlow N, Wolke D, Bracewell MA, Samara M. Neurologic and developmental disability at six years of age after extremely preterm birth. N Engl J Med 2005; 352: 9-19.

3 Bhutta AT, Cleves MA, Casey PH, Cradock MM, Anand KJ. Cognitive and behavioral outcomes of school-aged children who were born preterm: a meta-analysis. JAMA 2002; 288: 728-37.

4 Johnson S. Cognitive and behavioural outcomes following very preterm birth. Semin Fetal Neonatal Med 2007; 12: 363-73.

5 Goncalves LK, Chaiworapongsa T, Romero R. Intrauterine infection and prematurity. Ment Retard Dev Disabil Res 2002; 8: 3-13.

6 Romero R, Espinoza J, Kusanovic JP, et al. The preterm parturition syndrome. BJOG 2006; 113 (suppl 3): 118-35.

7 Jobe AH. Glucocorticoids, inflammation and the perinatal lung. Semin Neonatol 2001; 6: 331-42.

8 Dammann O, Leviton A. Inflammation, brain damage and visual dysfunction in preterm infants. Semin Fetal Neonatal Med 2006; 11: 363-68.

9 King J, Flenady V. Prophylactic antibiotics for inhibiting preterm labour with intact membranes. Cochrane Database Syst Rev 2002; 4: CD000246.

10 Kenyon SL, Taylor DJ, Tarnow-Mordi W. Broad-spectrum antibiotics for spontaneous preterm labour: the ORACLE II randomised trial. Lancet 2001; 357: 991-96.

11 Kenyon S, Pike K, Jones DR, et al. Childhood outcomes after prescription of antibiotics with preterm rupture of the membranes: 7-year follow-up of the ORACLE I trial. Lancet 2008; published online Sept 18. DOI:10.1016/S0140-6736(08)61202-7.

12 Saigal S, Rosenbaum P, Stoskupf B, et al. Comprehensive assessment of the health status of extremely low birthweight children at eight years of age: comparisons with a reference group. J Pediatr 1994; 125: 411.

13 Goodman R. The strengths and difficulties questionnaire: a research note. J Child Psychol Psychiatry 1997; 38: 581-86.
14 Asher MI, Keil U, Anderson HR, et al. International Study of Asthma and Allergies in Childhood (ISAAC): rationale and methods. Eur Respir J 1995; 8: 483-91.

15 Anon. Multi-attribute health status classification system: health utilities index mark 3 (HUI3). http://www.healthutilities. com/hui3.htm (accessed Aug 8, 2008)

16 Feeny D, Furlong W, Saigal S, Sun J. Comparing directly measured standard gamble scores to HUI2 and HUI3 utility scores: group- and individual-level comparisons. Soc Sci Med 2004; 58: 799-809.

17 Cuffe SP, Moore CG, McKeown RE. Prevalence and correlates of ADHD symptoms in the National Health Survey. J Atten Disorder 2005; 9: 392-40.

18 Qualifications and Curriculum Authority. Key stage 1 assessments and reporting arrangements. London: Qualificiations and Curriculum Authority, 2007.

19 Altman DG. Practical statistics for medical research. London: Chapman and Hall, 2006.

20 Montgomery AA, Peters TJ, Little P. Design, analysis and presentation of factorial randomised controlled trials. BMC Med Res Methodol 2003; 3: 26

21 Gates S. Brocklehurst P. How should randomised trials including multiple pregnancies be analysed? BJOG 2004; 111: 213-19.

22 Bland JM, Altman DG. Multiple significance tests: the Bonferroni method. BMJ 1995; 310: 170.

23 Tin W, Fritz S, Wariyer U, Hey E. Outcome of very preterm birth: children reviewed with ease at 2 years differ from those followed up with difficulty. Arch Dis Child Neonatal Ed 1998; 79: F83-87.

24 McAlister FA, Straus SE, Sackett DL, Altman DG. Analysis and reporting of factorial trials: a systematic review. JAMA 2003; 289: $2545-53$.

25 4Child. Four counties database of cerebral palsy, vision loss and hearing loss in children. Annual report, 2007. http://www.npeu. ox.ac.uk/downloads/4child/annual-report/4Child-annual-report2007.pdf (accessed Aug 11, 2008).

26 Kallen BA, Otterblad Olausson P, Danielsson BR. Is erythromycin therapy teratogenic in humans? Reprod Toxicol 2005; 20: 209-14.

27 Bedford Russell AR, Murch SH. Could peripartum antibiotics have delayed health consequences for the infant? BJOG 2006; 113: 758-65.

28 American College of Obstetricians and Gynecologists. Management of preterm labor. ACOG Practice Bulletin No 43. Obstet Gynecol 2003; 101: 1039-47. 